\title{
MONOCHORD TEL BÖLÜNMELERİ İLE ARMONİKLER ARASINDAKİ BAĞLANTI
}

THE RELATION BETWEEN MONOCHORD WIRE DIVISIONS AND HARMONICS

\author{
İlhami KAYA ${ }^{1}$
}

\section{$\ddot{O} z$}

Tarih öncesinde müzikal sesler, notalardan ziyade sayı ve oranlarla ifade edilmiştir. Bu alanda ilk çalışmalar, Antik Çin'de Ling Lun (MÖ 2700) ile başlayarak Antik Yunanda Pythagoras (MÖ 600) ve sonrasında sürdürülmüştür. Sayılarla veya oranlarla ifade edilen dizi ve aralıklarda, genellikle aritmetiğin bazı temel işlemleri kullanılmıştır. Aritmetik işlemlerle elde edilen müzikal seslerin gösterimi ise Pythagoras tarafindan tasarlanan monochord adlı tek telli çalgı ile sağlanmıştır. Bu çalışmada, Antik dönemde bilimsel yöntemlerle aritmetik ve müziğin etkileşiminde oldukça önemli olan monochord üzerinde yapılan deneylerle, 17. yüzyılda keşfedilen armonik seslerin oransal dizilimleri arasındaki bağlantı anlatılmaktadır.

Anahtar Kelimeler: Monochord, Armonikler, Sayı ve Oranlar

\begin{abstract}
In prehistoric times, musical sounds have been expressed with numbers and proportions rather than notes. The first studies in this area have emerged in ancient China (2700 BC) by Ling Lun and then maintained in ancient Greece (600 BC) by Pythagoras. In general, some basic arithmetic operations have been employed in the scales and tones which were expressed by the numbers or ratios. The representation of musical sounds obtained by arithmetic operations has been provided with a single-string instrument named as monochord designed by Pythagoras. In this study, the relation between the experiments carried out on monochord, which is quite important in terms of allowing the interaction of music and arithmetic through the scientific methods in ancient times, and the proportional sequence of harmonic sounds discovered in the $17^{\text {th }}$ century.
\end{abstract}

Keywords: Monochord, Harmonics, Number and Ratios.

\footnotetext{
${ }^{1}$ Batman Üniversitesi, Batı Raman Kampüsü, Güzel Sanatlar Fakültesi, Müzik Bölümü.
} 


\section{Pythagoras ve Ses Üzerine Yapılan Deneyleri}

Pythagoras'ın MÖ 6. yüzyılda müzikal aralıklar ve dizi kurulumu üzerine yapmış olduğu çalışmalar, müziği anlama ve bilimsel olarak açıklamanın ilk örneklerindendir. $\mathrm{Bu}$ keşif, Pythagoras'ın demirciler çalışırken çekiçlerden çıkan seslerin uyumundan etkilenmesi ile başlamıştır.

Demircilerin kullandığı çekiç ağırlıklarından esinlenerek müzikal ses aralıkları üzerinde deneyler yapan Pythagoras, ${ }^{2}$ farklı ağırlıktaki çekiçlerden çıkan seslerin uyumunu, ${ }^{3}$ tel boylarını veren büyüklüklerle oranlayarak, müzikteki ses aralıklarını oranlarla (basit kesirlerle) ifade etmiştir. Böylelikle Pythagoras, ses aralıklarının tel uzunluklarına ve tel uzunluklarının birbirine oranına bağlı olduğunu keşfetmiştir. Görsel 1'de Pythagoras'ın çekiç ve çekiç ağırlıkları ile yaptı̆̆ı deneyler temsili olarak betimlenmiştir.

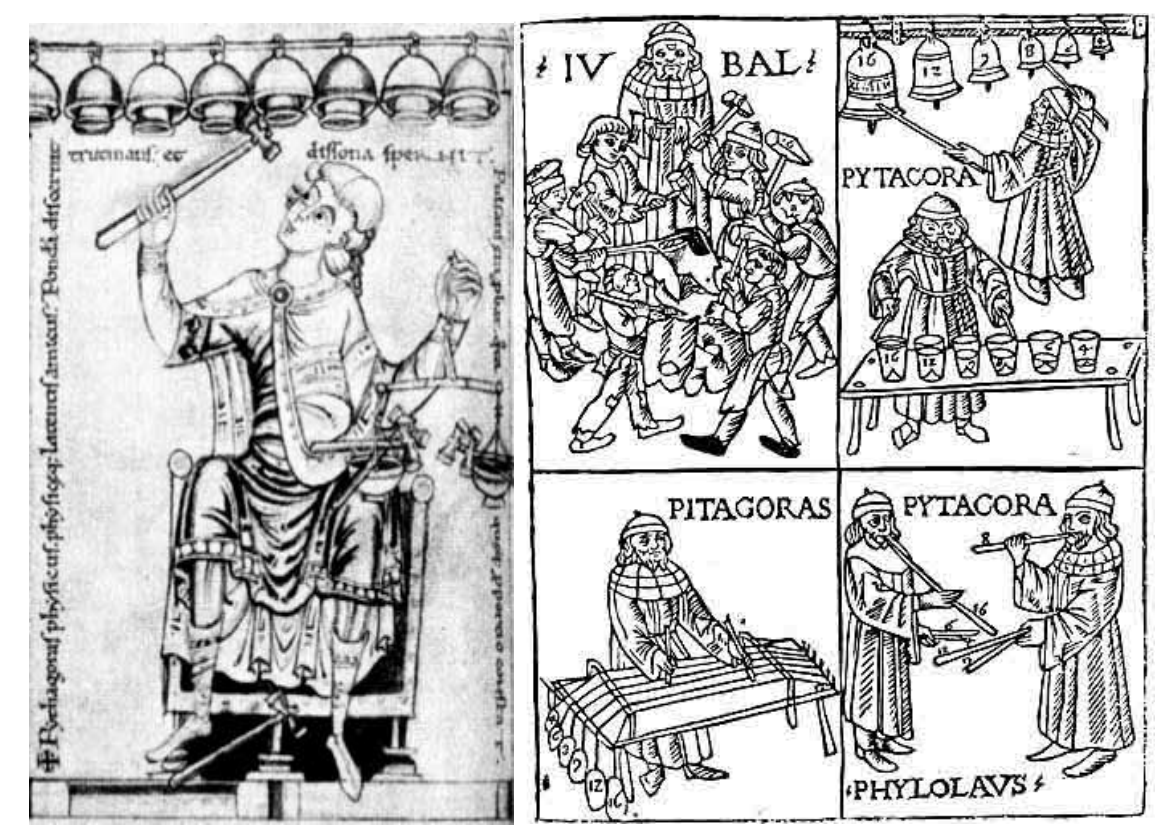

Görsel 1. Ses Deneyleri ${ }^{4}$

Evrenin bütününü sayılarla anlamlandırmaya çalışmış bir bilimci olan Pythagoras, müzik çalışmalarında küçük sayı değerleri ve basit kesirler kullanmıştır. Bu nedenle ilk olarak Pythagoras, farklı ağırlıktaki çekiçlerin çıkardıkları seslerin ses ahenginde önemli olduğunu ${ }^{5}$ ve çekiç ne kadar ağır ise çıkan sesin de o kadar pest olduğunu fark etmiştir. Daha sonra farklı olan çekiçlerin ağırlık birimlerini, birbiriyle oranlamıştır. Pythagoras'ın kullandığı ağırlık birimlerinde kullandığ 1 yöntem, küp şeklindeki bir cismin 12 ayrıt, 8 köşe ve 6 yan yüz sayıları ile benzerlik taşımaktadır. ${ }^{6}$ Diğer bir yöntem ise tekraktys ${ }^{7}$ adı verilen ilk dört sayma sayısının oluşturduğu düzendir. Görsel 2'de gösterimi yapılan tetraktys'ün tabanına ait nokta sayısının birbirine oranı, bir kesirli sayı oranını verir. Tetraktys'deki sayma sayılarının en küçük ortak katının 12 olması nedeniyle ilk çekiç ağırlığı 12 birim, diğer ağırlıklar ise 8 ve 6 birim olarak seçilmiştir. Çekiçlerin ağırlık birimleri, tetraktys'ü oluşturan 1, 2, 3 ve 4 sayıları ile orantılandığında, sayılar kendi aralarında $1: 2,2: 3$ ve $3: 4$ oranlarını verir.

\footnotetext{
${ }^{2}$ Uzay Bora, U.Ü. Eğitim Fakültesi Dergisi, 58

${ }^{3}$ Mark Lindley, Ronald Turner-Smith, Mathematical Models Scales, 223

${ }^{4}$ J. Fauvel- R. Flood- R. Wilson (2003), Music And Matematics, 5-12

${ }^{5}$ Thomas Christensen, The Cambridge History of Western Music Theory, 272

${ }^{6}$ Thomas Heath, A History Of Greek Mathematics, 85

${ }^{7}$ Guerino Mazzola, Elemente Der Musikinformatik, 5
} 


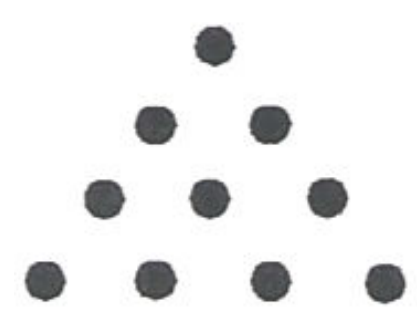

Görsel 2. Tetraktys

Çekiçlerin çıkardığı farklı seslerden elde ettiği bulguları Pythagoras, işitme duyusuna anlamaya yardımcı olacak biçimde çalgı tellerine de uygulamıştır. İki duvar arasına çapraz olarak çaktığı kazığa, dört ayrı tel gererek tel uçlarına bağlanan farklı ağırlıkların gerilen tellerdeki etkisini incelemiştir. ${ }^{8}$ Yapılan deneylerle tel uzunluklarının, doğal sayıların birbirine oranlarına bağlı olduğunu bulan Pythagoras, ${ }^{9}$ iki telin birbirine olan oranı kullanarak farklı ses aralıkları aramış ve monochord adı verilen tek telli bir müzik aleti ile bu deneylerin gösterimini sağlamıştır. Monochord, ${ }^{10}$ Antik Yunan armonik teorisinde sayısal oranlara göre müzikal aralıklarla üretmek için hareketli köprü ile bir telin ses perdelerinin tam yerleşimini sağlamak için inşa edilen çalgıdır. ${ }^{11}$ Yazar tarafından Pythagoras monochord tasarımına uygun ve tel uzunluğu $60 \mathrm{~cm}$ olarak hazırlan çalgı örneği Görsel 3'de gösterilmiştir.
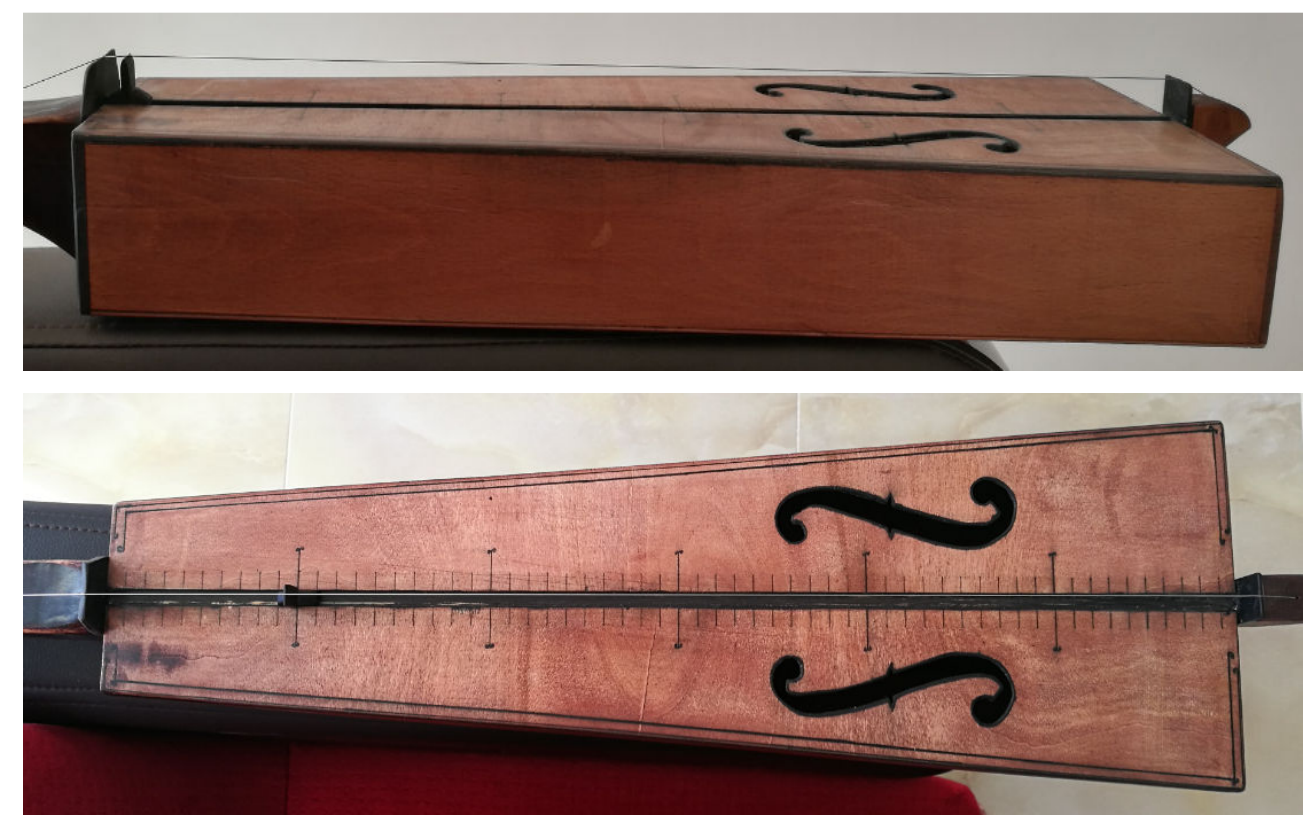

Görsel 3. Monochord

\section{Monochord Tel Bölünmeleri}

\footnotetext{
${ }^{8}$ Derman Bayladı, Pythagoras Bir Gizem Peygamberi, 92

${ }^{9}$ Jerry P. King, Matematik Sanatı, Çev. Nermin Arık, 44

${ }^{10}$ Monochord aynı zamanda kanon adiyla da bilinir.

${ }^{11}$ David Creese, Chicago Journals, 549

Ancient Greek harmonic theory made much use of the kanon, or monochord, built around a graduated ruler that allowed precise placement of movable bridges to stop a string and produce musical intervals according to specified numerical ratios.
} 
Monochord adlı çalgının tel boyunu değiştirerek farklı sesler elde eden Pythagoras, sesleri veren tel uzunluklarının birbirlerine göre oranlarını kıyaslamıştır. Yapılan deneylerde tıpkı çekiç ağırlığının azalmasında olduğu gibi, tel boyunun kısalması ile çıkan sesler incelir. Boyu L olan bir tel Görsel 4'te görüldüğü gibi iki eşit parçaya bölündüğünde, telin her bir parçası ilk sesin incesini verir. Başlangıçtaki sesin oktavını veren bu ses, Pythagoras'a göre en küçük orana sahip, ilk uyumlu aralık oranıdır. Görsel 4'te monochord'un iki eşit parçaya bölünmesi ile $60 \mathrm{~cm}$ olan tel boyu her iki kısımda da tel boyu $30 \mathrm{~cm}$ biriminde kalır. İki eşit parçaya bölünmüş çalgının her iki kısmında başlangıç sesinin oktavı yer alır.

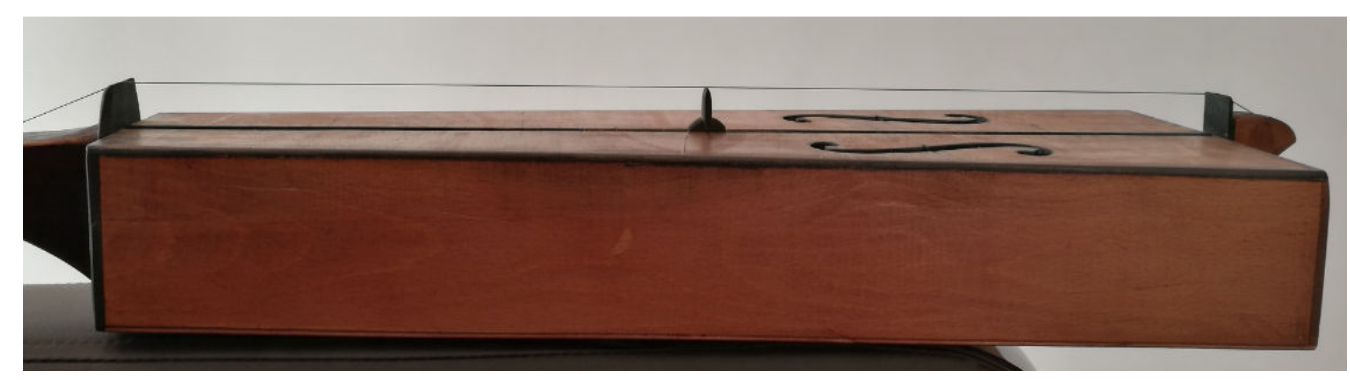

Görsel 4. Monochord'un İki Eşit Paraya Bölünmesi

Başlangıçta L boyuna sahip olan tel do $\left(\mathrm{C}^{12}\right)$ sesini veriyor iken, tel boyu yarılandığında, $\frac{1}{2} \times \mathrm{L}$ tel boyu ile oktavı olan ince do (C5) sesini verir. Tel boyunun yarılanması ile elde edilen C4 ve C5 seslerinin portedeki yerleri (Örnek 1) sırasıyla Görsel 5a ve 5 b'de gösterilmiştir.

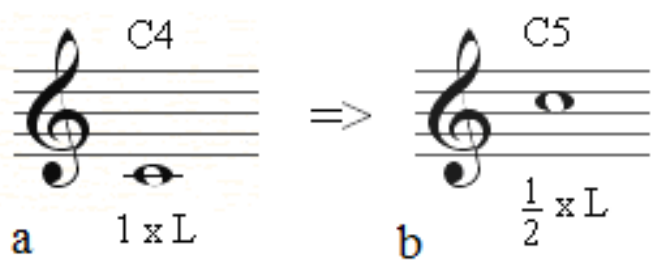

Görsel 5. Nota Örneği (Örnek 1).

Tel boyu üç eşit parçaya bölündüğünde mükemmel beşli olan doğal tam beşli aralığ1 elde edilir. Doğal tam beşliyi, telin üçte ikisi oluşturur. Görsel 6'da monochord'un üç eşit parçaya bölünüşü görülmektedir. Monochord'un üç eşit parçaya bölünmesi ile tel boyu 20 ve $40 \mathrm{~cm}$ olur. Her iki tel boyu başlangıç sesinin beşlisini ve beşlinin oktavını verir.

\footnotetext{
${ }^{12}$ Piyano gibi çalgılarda do sesinin dördüncü oktavını temsil eder.
} 


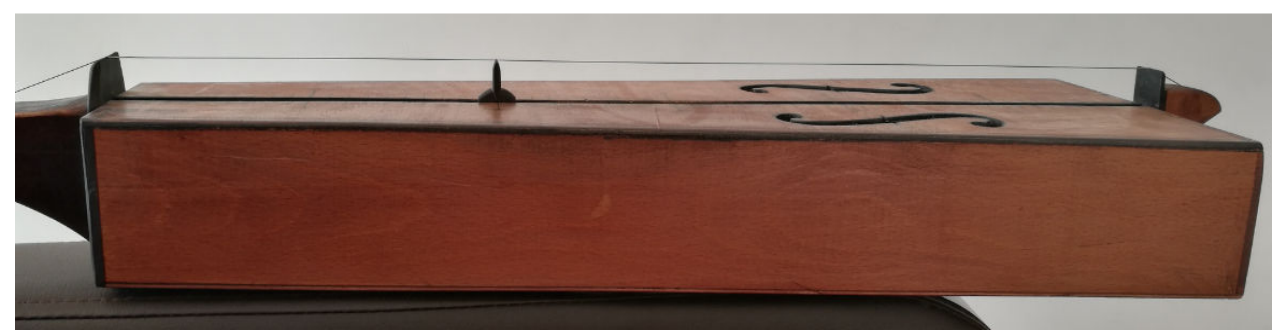

Görsel 6. Monochord'un Üç Eşit Paraya Bölünmesi

Tel üç eşit parçaya bölündüğünde, L başlangıç boyuna sahip tel do (C4) sesini vermekte iken, $\frac{1}{3} \times \mathrm{L}$ boyuna ulaştığında oktavı olan ince sol (G5) sesini verir. Bu telin iki katı olan diğer parçası olan $\frac{2}{3} \times \mathrm{L}$ tel boyu ise sol (G4) sesini verir. C4,G4 veG5 seslerinin portede yerleri ve bu seslere karşı gelen tel boyları sırasıyla Görsel 7a, 7b ve 7c'de gösterilmiştir (Örnek 2).

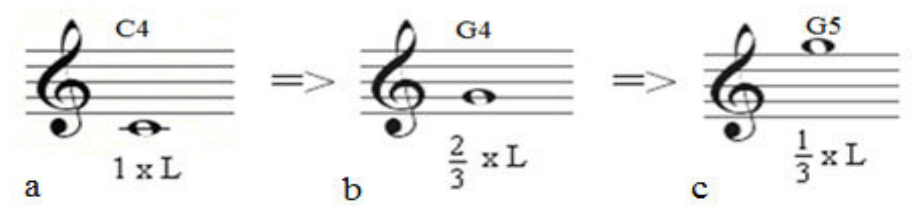

Görsel 7. Nota Örneği (Örnek 2).

Monochord üzerinde tel boyu dört eşit parçaya bölündüğünde, L başlangıç boyuna sahip ve do (C4) sesini veren telin bir parçası $\frac{1}{4} \times \mathrm{L}$ boyuna sahip olur ve iki oktav ince do (C6) sesini verir. Bu çeyrek boya sahip tel, $\frac{1}{2} \times \mathrm{L}$ uzunluğundaki telin iki eşit parçaya bölünmüş halidir. Görsel 8 'de monochord'un dört eşit parçaya bölünüşü gösterilmiştir. Monochord'un dört eşit parçaya bölünmesi ile tel boyu 15 ve $45 \mathrm{~cm}$ olur. $15 \mathrm{~cm}$ olan tel boyu başlangıç sesinin iki oktav incesini $45 \mathrm{~cm}$ olan tel boyu ise başlangıç sesinin dörtlüsünü verir.

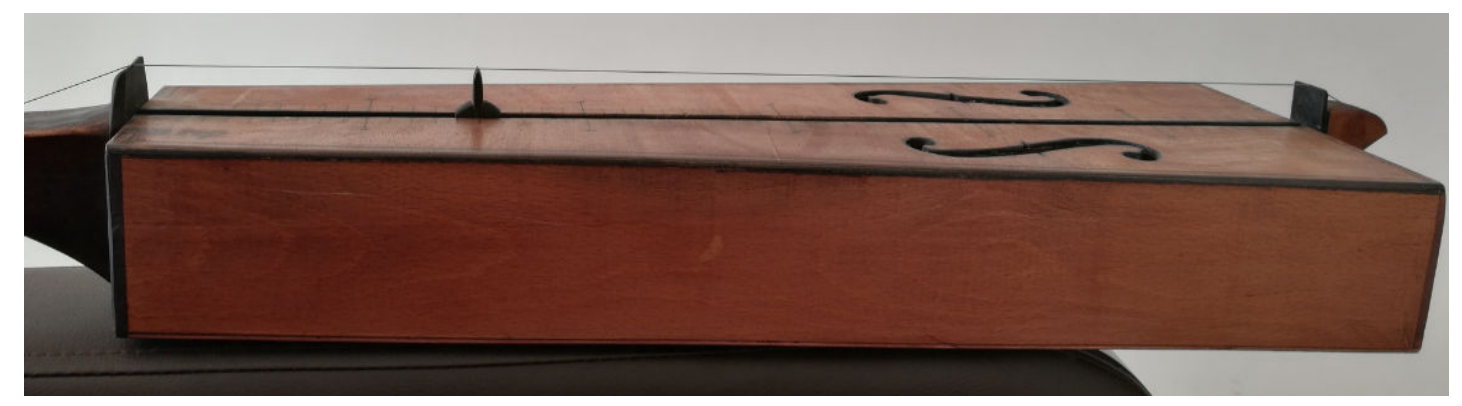

Görsel 8. Monochord'un Dört Eşit Paraya Bölünmesi

Dört eşit parçaya bölünen L boylu telin diğer kısmı, $\frac{3}{4} \times \mathrm{L}$ boyundaki tel boyuna sahiptir ve fa (F4) sesini verir. Elde edilen $\frac{3}{4} \times \mathrm{L}$ boyundaki tel, $\frac{1}{4} \times \mathrm{L}$ boyundaki telin üç 
katıdır (Örnek 3). Bu örnekte elde edilen seslerin portedeki yerleri sırasıyla Görsel 9a, 9b ve 9c'de gösterilmiştir.

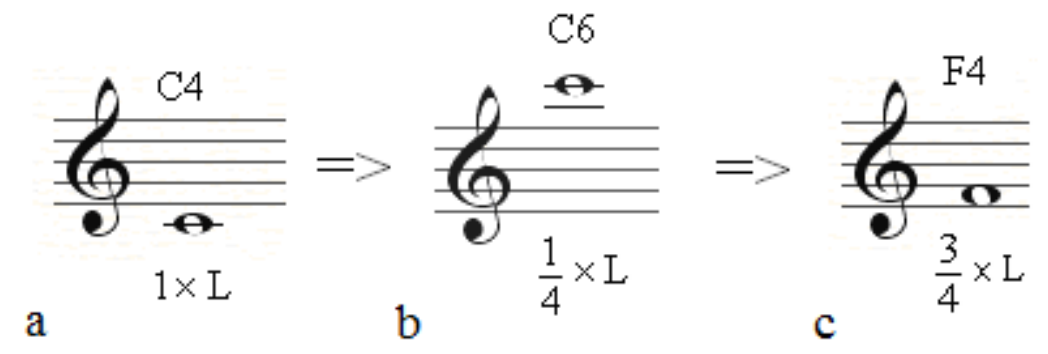

Görsel 9. Nota Örneği (Örnek 3).

Pythagoras, farklı sesleri veren tel uzunluklarını birbirleriyle oranlayarak, müzikal aralıkları iki tam sayının oranı olarak ifade etmiştir. Aynı zamanda Pythagoras, tel boyu uzunluğuna sahip iki monochord ile farklı tel boylarından çıkan uyumlu ses aralık oranlarını saptamıştır. Pythagoras bilimsel yönden astronomi ile armoninin kardeş olduğu görüşüne inanmaktadır. ${ }^{13} \mathrm{Bu}$ nedenle Pythagoras yaptı̆̆ müzik deneyleri sonucunda; astronomi ile armoninin evrendeki en temel gerçek ahenk olduğunu ve en yüksek ahengin de müzikte olduğunu savunmuştur. ${ }^{14}$ Yaptığı tüm deneyler sonucunda Pythagoras, ses aralıklarının tel boylarına bağlı olduğunu ve tel boyu oranları ile sınıflandırılabileceğini saptamıştır. ${ }^{15} \mathrm{Bu}$ sayede müzikal aralıkları iki tam sayının birbirine oranı ile temsil edip, tel boyu oranlarını büyükten küçüğe sıralayarak, kendi adıyla anılan Pythagoras dizisini oluşturmuştur.

\section{Armonikler}

Antik Yunan'da, aralıklar tel boyu ile temsil edildiğinden, bir telin türetebildiği birden fazla armonik hakkında bilimsel olarak bir tanım yoktur. Fakat tel boyu oranlarında kullanılan pay ve payda değerleri, armonikler hakkında bilgiler bulmamıza yardımcı olur. Bunun için oranlarda kullanılan küçük terimin büyük terime olan oranı hesaplanır. Örneğin ikinci armoniğin tel boyu katsayısının üçüncü armoniğin tel boyu katsayısına oranı 2:3'ü verir. Elde edilen bu oran, beşli aralığı temsil eder. Bu nedenle armonikler üzerine yapılan çalışmaların Antik Yunan'dan başladığı söylenilebilir.

Pythagoras'ın bir teli bölerek yaptığı çalışmalarda, armonik ses oranlarını gözlemlemek mümkündür. $\mathrm{Bu}$ nedenle, armoniklerin altında yatan matematiksel oranları keşfeden ilk filozof olarak bilinmektedir. ${ }^{16}$ Araştırmaları, ses akustiğine dair yapılan ilk deneysel çalışma niteliğini taşır. Bu dönemde armonikleri betimleyen yeterli bir ifade ve tanım bulunmasa da, üst armoniklerin Ptolemy (90-168) ve Gioseffo Zarlino (1517-1590) gibi düşünürlerin yaptığı çalışmalardan sonra $^{17}$ keşfedildiği söylenilebilir. ${ }^{18}$ Ptolemy, Pythagoras'ın kullanmadığı üçlü ve altılı aralıkları kullanmıştır. Zarlino ise Ptolemy'nin yaptığı çalışmaları geliştirmiş ve just intonation için uyarlamıştır. Ptolemy, armonik dizinin duysal olarak öne çıkan ilk beş aralığı olan oktav, beşli, dörtlü, majör üçlü ve minör üçlü

\footnotetext{
${ }^{13}$ Andre Barbera, The American Journal Of Philology, 397

${ }^{14}$ Bkz. (7), BAYLADI, 92

${ }^{15}$ James Jeans, Science And Music, 362

${ }^{16}$ Bkz.(4), CHRİSTENSEN,272

${ }^{17}$ Zarlino, Ptolemy’nin dizileri üzerinde yaptığı çalışmalardan dolayı, Antik Yunan'da bu tür çalışmaların olduğu söylenilebilir.

${ }^{18}$ Matthew T. Grenfell, The Development of The Equal Temperament Scale Evolution or Radical Change, 27

These two philosophies were later brought closer together with the discovery of overtones.
} 
aralığına açıklık kazandırmıştır. ${ }^{19}$ Zarlino, Pythagoras'ın monochord tel bölünmelerinde kullandığ1 prensip olan tekraktys düzenini genişletmiştir. ${ }^{20}$ Monochord tel bölünmelerine uygulanan bu düzen sayesinde Pythagoras'ın kullanmadığı aralıklar (majör üçlü ve minör üçlü) elde edilmiştir.

Armonikler hakkında ilk anlamlı bilimsel çalışma, Fransız matematikçi Marin Mersenne $^{21}$ (1588-1648) tarafindan yayınlanmıştır. ${ }^{22}$ İlk bilimsel açıklama, Fransız akustikçi Joseph Sauveur (1653 - 1716) tarafından yapılmıştır. Belirli bir perdedeki titreşimlerin sayısını hesaplayan Sauveur, bir temel sesin üst armoniklerinin olduğunu savunmuştur. ${ }^{23}$

[...Doğada duyulan ses, kendi içerisinde sayısız sinüs dalgası barındırır. Duyulan bir sesin içyapısında yer alan farklı frekanslardaki bu sinüs dalgalarına, sesin doğuşkanları ya da armonik tayfı adı verilir... $]^{24}$ Tek bir sesin beraberinde taşıdığı diğer sesler, Görsel 10' da gösterilmiştir.

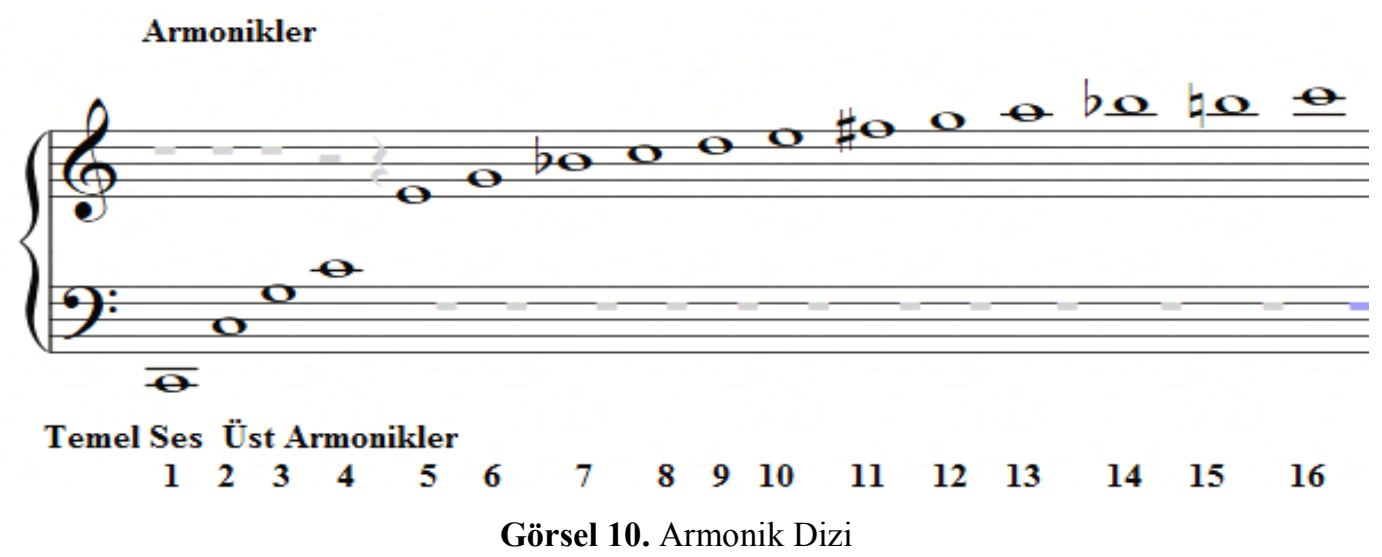

Armonikler hakkında yeterli kavram ve tanımlamalar 17. yüzyılda yapılabilmiştir. Jean Philippe Rameau (1683-1764), armonik frekanslarının temel sese ait frekansın katları olduğunu $^{25}$ ve katsayıların pozitif tamsayılardan oluştuğunu keşfetmiştir. Bu tanıma göre temel ses perdesi $1 \mathrm{x}$ temel frekans, ikinci armonik frekans1 $2 \mathrm{x}$ temel frekans, üçüncü armonik frekansı 3x temel frekans olur. Her armonik, temel ses dâhil, 1'den başlayarak ardışık tamsayılar ile temsil edilir. Bu tamsayılar aynı zamanda tonu üreten telin, kaça bölündüğünü

${ }^{19}$ J. Murray Barbour, Tuning And Temperament, 2

Ptolemy's syntonic diatonic has especial importance to the modern world because it coincides with just intonation, a tuning system founded on the first five intervals of the harmonic series octave, fifth, fourth, major third, minor third. Didymus' diatonic used the same intervals, but in slightly different order.

${ }^{20}$ Bkz.(4), CHRISTENSEN, 277.

... a conceptual extension of the Pythagorean tetractys, comprising the integers from 1 to 6 .

${ }^{21}$ Harmonie universelle adlı kitabidir.

${ }^{22}$ M. T. Grenfell, The Development of The Equal Temperament Scale Evolution or Radical Change, 27

The Greeks wrote about the harmonic series for interval string lengths, but not for multiple pitches simultaneously produced on one string. The first publication of this knowledge was by French mathematician Marin Mersenne.

${ }^{23}$ Eduardo J. Calle, Music as a Branch of Mathematics, 10

French acoustician Joseph Sauveur $(1653$ - 1716) as the first person to calculate the number of vibrations by a specific pitch and also offered the first scientific explanation for upper partials of a fundamental tone called overtones.

${ }^{24}$ İlke Boran, Elektronik Müzikte Analog Dönem ve Bülent Arel’in Stereo Elektronic Müsic No. 1 Adlı Yapıtı, 15

${ }^{25}$ Saloni Shah, An Exploration of the Relationship between Mathematics and Music, 33

Rameau discovered that the harmonic frequencies are multiples of the frequency of fundamental tones, and these multiples are given by the positive integers 
de belirtir. Örneğin; temel sesi veren birinci armoniğin tel uzunluğu ikiye bölündüğünde ikinci armonik, üçe bölündüğünde üçüncü armonik tınlar. ${ }^{26}$ Aynı zamanda armonik dizi, herhangi bir temel frekansın tamsayı katları ile oluşan frekanslar dizisidir. Birinci armoniğin frekans1 $\mathrm{f}$ ise ikinci armoniğin frekans1 2f, üçüncü armoniğin frekans1 $3 \mathrm{f}$ ile gösterilir. Armonikler dizisi (f, 2f, 3f, 4f, ...) kümesi ile gösterilir. Temel sesin frekansı $\mathrm{f}=55 \mathrm{~Hz}$ ise ikinci armoniğin frekansı 2 x f $=110 \mathrm{~Hz}$, üçüncü armoniğin frekansı $3 \times \mathrm{f}=165 \mathrm{~Hz}$. olur.

Tablo 1'de temel frekans ve katsayıları gösterilmiştir.

\begin{tabular}{|l|l|l|l|l|l|l|}
\hline Armonikler & af & $3 \mathrm{f}$ & $4 \mathrm{f}$ & $5 \mathrm{f}$ & $6 \mathrm{f}$ & $7 \mathrm{f}$ \\
\hline $55 \mathrm{hz}$ & $110 \mathrm{hz}$ & $165 \mathrm{hz}$ & $220 \mathrm{hz}$ & $275 \mathrm{hz}$ & $330 \mathrm{hz}$ & $385 \mathrm{hz}$ \\
\hline Temel Ses & \multicolumn{1}{|l}{ Üst armonikler } & & & \\
\hline
\end{tabular}

Armonikler dizisi irdelendiğinde, müzikal aralıklara ait oranları da saptamak mümkün olur. Tam beşli aralığı, dizinin ikinci ve üçüncü armonikleri arasında yer alır. Üçüncü armonik frekans katsayısının ikinci armonik frekans katsayısına oranı, beşli aralığ temsil eden 3:2 oranını verir. Bu sayede iki perde aralarında karşılaştırıldığında frekans oranlarını belirlemek mümkün olur. İki perde arasındaki uzaklık, aralık olarak tanımlanır ve oranlar ile de temsil edilir. ${ }^{27} \mathrm{Bu}$ oran ve aralıkların, monochord tel bölünmelerinde de aynı sonucu verdiği görülmektedir.

İlk armonikler uyumlu aralık oranlarını verir. Armonikler dizisinde uyumlu ses aralıkları temel sese yakın olan aralıklardır. Dizinin elemanları başlangıç sesten uzaklaştıkça, elde edilen yeni aralıklar uyumsuz aralık olma niteliği taşır. Örneğin yedinci armoniğe dek uyumlu aralıkların (yedinci armonik hariç) yer aldığ 1 görülmektedir. Temel nedenini İlke BORAN, "Doğuskanlar arasındaki frekans farkı hep aynı kalırken, doğuskanların aralıkları tize çıktıkça daralmaktadır. Bunun nedeni, eklenen frekansın tize çıktıkça artan frekans sayısına oranının küçülmesine bağlıdır, ${ }^{, 28}$ şeklin de açıklamıştır.

Armonikler dizisi, müzikal yapı ve algı hakkında plan oluşturmaya yarar. Bu nedenle de armonik ayarın temel kuralları, matematiksel önermelerden çok insan algısı ve besteleme alışkanlıkları üzerine temellenir. Akustik süreç herkes tarafından kendince yorumlanabilmektedir. ${ }^{29}$ Temel ses, sıklıkla tekrarlandığından yeri belirginleşir. Armonik arasından çift sayılı konumda olanlar tekrarlandığından tek sayılı konumdaki armonikler kolayca saptanır. ${ }^{30}$ Aynı zamanda müziği oluşturan melodi, armonikler tarafından şekillenir.

\footnotetext{
${ }^{26}$ Pythagoras'ın yaptığı çalışmalarla benzerlik taşısa da duyusal olarak Antik Yunan'da doğuşkanlarla ilgili bilgi karşımıza uyum olarak çıkmaktadır.

${ }^{27}$ Xaq Pitkow, Why Do Oktaves Sound The Same, 3

The natural comparison between two pitches is the ratio between their respective frequencies. These ratios define the interval between two pitches.

${ }^{28}$ İlke Boran, Elektronik Müzikte Analog Dönem ve Bülent Arel’in Stereo Elektronic Müsic No. 1 Adlı Yapitı, 16

${ }^{29}$ Linas Plankis, The Two-Dimensional Tuning, 9

The main law of harmonic tuning is based on human understanding and traditions of composing gamuts rather than on mathematical premises. So that one won't find respective ideas among laws, that describe actual acoustic processes. And we could compare this law with laws of perspective in drawings and pictures, which ones are more connected with our inner imagination than with real 3-dimensional world. However in the both cases, both with tuning and with pictures perspective, respective definitions have undoubted regular references with reality, that not allow to keep these laws purely fictional.

${ }^{30}$ Johnny Reinhard, 8th Octave Overtone Tuning, 1
} 
Melodi, birbiri ardından hareket eden perdeler (frekanslar) dizisidir. ${ }^{31}$ Bu nedenle de herkesin algısına ve bakış açısına göre değişmektedir.

Armonik dizide sıklıkta tekrar eden temel ses, yapılan ayarı sabitlemek ve diğer armoniklerin yerini saptamak için önemlidir. Armonik dizinin bir alt kümesi (f, qf, $q^{\wedge} 2 f, q^{\wedge} 3 f$, $\left.\mathrm{q}^{\wedge} 4 \mathrm{f}, \ldots\right)$ ile temsil edilen geometrik bir dizidir. ${ }^{32}$ Geometrik dizide her yeni terim bir öncekinin sabit bir q çarpan katıdır. ${ }^{33}$ Örneğin bir sesin oktavları q=2 için bir geometrik dizi oluşturulmak istenildiğinde, temel sesin frekansı $55 \mathrm{~Hz}$ olan A perdesinin oktav1 2 x $55=110$ $\mathrm{Hz}$, ikinci oktavı $2 \times 2 \times 55=220 \mathrm{~Hz}$, üçüncü oktavı ise $2 \times 2 \times 2 \times 55=440 \mathrm{~Hz}$ frekansına sahip olur. Tüm bu verileri açıklamak için ilk önce birinci (C), ikinci (C), dördüncü (C), sekizinci $(C)$ ve diğer armoniklerin yeri tespit edilir. Bir diğer armonik olan üçüncü $(\mathrm{G})$, altınc1 $(\mathrm{G})$, on ikinci $(\mathrm{G})$ ya da beşinci $(\mathrm{E})$, onuncu $(\mathrm{E})$, yirminci $(\mathrm{E})$ ve yedinci $(\mathrm{Bb})$ olan diğer armoniklerde aynı yöntemle yerleştirilir. Sıralamada sekizinci ile on altıncı armonikler arasında majör bir diyatonik dizi oluşur. $\mathrm{Bu}$ yöntem diğer armonikler arasında uygulandığında, ses oranlarının ve perdelerinin kullanılabilirliği artmış olur.

Monochord'u bölmek için kullanılan prensipler, frekansın doğal karşılığına ${ }^{34}$ eşittir. Temel frekansta içinde yer alan bu çoklu iç frekanslara armonikler denildiği gibi bu yapı ile birlikte oluşan doğal dizilim de armonik dizi olarak tanımlanır. ${ }^{35}$ Monochord tel bölünmelerinde telin her iki kısmında yer alan sesler hem armonik dizi seslerini, hem de oranlarını sıralanmış bir biçimde verir. Örneğin armonik dizide 1. armonik ile 2. armonik arasında yer alan oktav ses oranı (C-C), monochord'un iki eşit parçaya bölünmesi ile başlangıç sesinin oktavı olan $1 / 2$ oranını (C-C) her iki kısımda da içinde barındırır. Armonik dizinin 2. armoniği ile 3. armoniği arasında yer alan beşli aralık (C-G) oran1, monochord'un üç eşit parçaya bölünmesi ile başlangıç sesinin beşlisi olan $2 / 3$ oranını (C-G), 1/3 oranı ise beşli aralık oktavını verir. Armonik dizinin 3. armoniği ile 4. armoniği arasında yer alan dörtlü aralık (G-C) oranı, monochord'un dört eşit parçaya bölünmesi ile başlangıç sesinin dörtlüsü olan 3/4 oranını (C-F), 1/4 oranı ise iki oktav sonraki başlangıç sesini (C) verir. Armonik dizinin 4. armoniği ile 5. armoniği arasında yer alan majör üçlü aralık (C-E) oranı, monochord'un beş eşit parçaya bölünmesi ile başlangıç sesinin majör üçlüsü olan $4 / 5$ $\operatorname{oranın1}^{36}$ (C-E), 1/5 oran1 $^{37}$ ise iki oktav sonraki majör üçlü sesini verir. Armonik dizinin 5. armoniği ile 6. armoniği arasında yer alan minör üçlü aralık (E-G) oranı, monochord'un altı eşit parçaya bölünmesi ile başlangıç sesinin minör üçlüsü olan $5 / 6$ oranın1 ${ }^{38}$ (C-Eb), 1/6 oranı $^{39}$ ise iki oktav sonraki beşli aralığını verir.

The harmonic series serves as a blueprint for musical connections and reception. It is a mode because the fundamental repeats most often throughout the harmonic series, and it is large enough a set of musical intervals as to not require modulation. Only the odd number harmonics appear in the overtone series because the evennumber harmonics are essentially duplicates.

${ }^{31}$ Matthew T. Grenfell, The Development Of The Equal Temperament Scale, 12

Melody is an element of music shaped by harmonics. Melody is a series of pitches (frequencies) layed one after another.

${ }^{32}$ Aynı zamanda bu büyüklük logaritmik olduğunu göstermektedir.

${ }^{33}$ Mark Petersen, Mathematical Harmonies, 4

The sequence of frequencies of these octaves: 55, 110, 220, 440,É is a geometric sequence. A geometric sequence is a sequence where the previous term is multiplied by a constant.

${ }^{34} \mathrm{Tel}$ boyunun tersi olarak da ifade edilir.

${ }^{35}$ Brian Timothy, Harlan, A Reconciliation of Harry Partch's Disparate Theories, 19 The principles used to divide the monochord, then, corresponded to the natural ordering of frequencies, which equally applies to the infrastructure of frequencies. These multiple internal frequencies within a fundamental frequency are called harmonics, and the natural ordering of harmonics is known as the harmonic series.

${ }^{36}$ Monochord üzerinde tel boyu $48 \mathrm{~cm}$ 'dir.

${ }^{37}$ Monochord üzerinde tel boyu $12 \mathrm{~cm}$ 'dir.

${ }^{38}$ Monochord üzerinde tel boyu $50 \mathrm{~cm}$ 'dir.

${ }^{39}$ Monochord üzerinde tel boyu $10 \mathrm{~cm}$ 'dir. 
Batı Müziğinin temelini başta tını olmak üzere akorların oluşumunda armoniklerin büyük bir önemi vardır. Öte yandan armoniklerle bir müzikal ses sistemi üretilebilmek de mümkündür. ${ }^{40}$ Just intonation armoniklerle üretilebilen bir müzikal ses sistemidir. Bu nedenle de armonik dizide yer alan hiçbir aralık oranı kurgusal değildir. Sesin doğal titreşiminin sonucu olarak elde edilen mükemmel oranlardan ibarettir. Armonikler yardımı ile ayar yapılırken bu oranlardan yararlanılır.

\section{SONUÇ}

Pythagoras çalışmaları seslerin birbiri içinde uyumunu konu edindiğinden, küçük olan sayı oranlarını en uyumlu aralıklar olarak görmüştür. Bu nedenle monochord tel bölünmeleri belli bir sınırda tutulmuştur. Yapılan çalışmalar monochord prensipleri armoniklerin sıralı olarak ispatını ortaya koymaktadır. Pythagoras bir teli iki, üç ve dört eşit parçaya bölerek (1/1, $1 / 2,2 / 3$ ve 3/4) ilk dört armonik ses oranını bulmuştur. Guiseffo Zarlino'nun Pythagoras monochord tel bölünmelerini genişletip altı eşit parçaya kadar çıkarması da (1/1, 1/2, 2/3, 3/4, $4 / 5$ ve 5/6) ilk altı armonik oranını elde etmesini sağlamıştır. Marin Mersenne'in yedinci armoniği keşfetmesi ile $(1 / 1,1 / 2,2 / 3,3 / 4,4 / 5,5 / 6$ ve $6 / 7)$ ilk yedi armonik oran elde edilmiştir.

Armonik dizi içerisinde yer alan oranlarla elde edilen aralıklar, monochord tel bölünmelerinde yer alan aralık oranları ile aynı değeri almaktadır. Monochord tel bölünmeleri ile bölünen telin her iki kısmı incelendiğinde hem armonik dizide yer alan aralığın oranını, hem de o armonik ses sıralamasını bir arada görmek mümkündür. Bu çalışmada yer alan verilerin monochord tel bölünmeleri ile armonikler arasında bir bağlantı olduğuna işaret ettiği görülmüştür. Doğal yöntemlerin kullanıldığı monochord tel bölünmeleri doğal titreşimlere sahip armoniklerin de doğal bir yapılanma sergilediğini göstermektedir. Bu nedenle ses sistemlerinin incelenmesinde monochord tel bölünmeleri ve armonikler başvurulması gereken kaynaklar olarak karşımıza çıkmaktadır.

\section{KAYNAKÇA}

BARBERA Andre (1981), Another Look At Plato And The Pythagoreans, The American Journal Of Philology, 102, 4, Winter, 395-410

BARBOUR, J. Murray (1951), Tuning and Temperament, Michigan State College Press, USA.

BAYLADI, Derman (2008), Pythagoras Bir Gizem Peygamberi, Say Yayınları, İstanbul.

BORA, Uzay (2002), Bilim Ve Sanatın Kesiştiği Temel Bir Nokta: Matematik Ve Müzik İlişkisi, U.Ü. Eğitim Fakültesi Dergisi, XV, 1, 53-68

BORAN, İlke (2007), Elektronik Müzikte Analog Dönem ve Bülent Arel'in Stereo Electronic Music No. 1 Adlı Yapıtı, Yayınlanmamış Doktora Tezi, MSGSÜ, İstanbul.

CALLE, Eduardo J.(2007), Music as a Branch of Mathematics, A Document and Presentation Prepared for The Mathematics Across the Community College Curriculum, Miami Dade College, USA.

CREESE, David (2011), "The Monochord in Ancient Greek Harmonic Science", Chicago Journals, Vol. 102, No. 3 September, 549-550, USA.

\footnotetext{
${ }^{40}$ Nicholas, Hender, Tuning Systems Derived from Timbre and Timbres Derived from Tuning Systems, as Realised in Electronic Music, 5... and if most timbres used in Western music are made up of harmonic partials, then a tuning system derived from the harmonic series would provide acoustically consanan intervals and chords, and hence more effective resolition of unstable harmonies.
} 
CHRISTENSEN, Thomas (2002), The Cambridge Hiatory Of Western Music Theory, Cambridge University Press, New York

FAUVEL J. - FLOOD R. - WİLSON R. (2003), Music And Mathematics, Oxford University Pres, New York.

GRENFELL, Matthew T. (2005), The Development of The Equal Temperament Scale Evolution or Radical Change, Unpublished Disertation, The Faculty of Western Connecticut State University, Danbury, USA.

HARLAN, Brian Timothy (2007), One Voice: A Reconciliation of Harry Partch's Disparate Theories, Unpublished PHD, University of Southern California, USA.

HEATH, Thomas (1921), The History Of Greek Mathematics, The Clerendon Pres, New York

HENDER, Nicholas (1997), Tuning Systems Derived from Timbre and Timbres Derived from Tuning Systems, as Realised in Electronic Music, Unpublished Honours Thesis, La Trobe University, Avustralya.

JEANS, James (1968), Science And Music, Dover Publicantion, New York

KING, Jerry P. (1992), Matematik Sanatı, Çev. Nermin Arık, Nurol Matbaacılık, Ankara

LINDLEY Mark - SMITH Ronald Turner (1993), Mathematical Models Of Musical Scales, Verlag Für Systematische Musikwissenschaft, Bonn.

MAZZOLA, Guerino (2000), Elemente Der Musikinformatik, Birkhaeuser Verlag, Zurih.

PETERSEN, Mark (2001), Mathematical Harmonies, http://people.math.sc.edu/sharpley/math750/MathMusic.pdf.

PITKOW, Xaq (2000), Why Do Oktaves Sound The Same, Preliminary Qualifying Exam for Harvard Biophysics, USA.

PLANKIS, Linas (2005), The Two-Dimensional Tuning, Project, Litvanya.

REINHARD, Johnny (2011), 8th Octave Overtone Tuning, American Festival of Microtonal Music, USA.

SCHIMMEL, ANNEMARİE (2000), Sayıların Gizemi, Çev. Mustafa Küpüşoğlu, Kabalcı Yayınevi, İstanbul

SHAH, Saloni (2010), An Exploration of the Relationship between Mathematics and Music, Unpublished Disertation, Manchester Institute for Mathematical Sciences School of Mathematics, UK. 